\title{
A Manifestação da Solidariedade em Adolescentes - Um Estudo Sobre a Personalidade Moral ${ }^{1}$
}

The manifestation of solidarity in adolescents a study of the moral personality

Denise D'Aurea-Tardeli

Unisantos

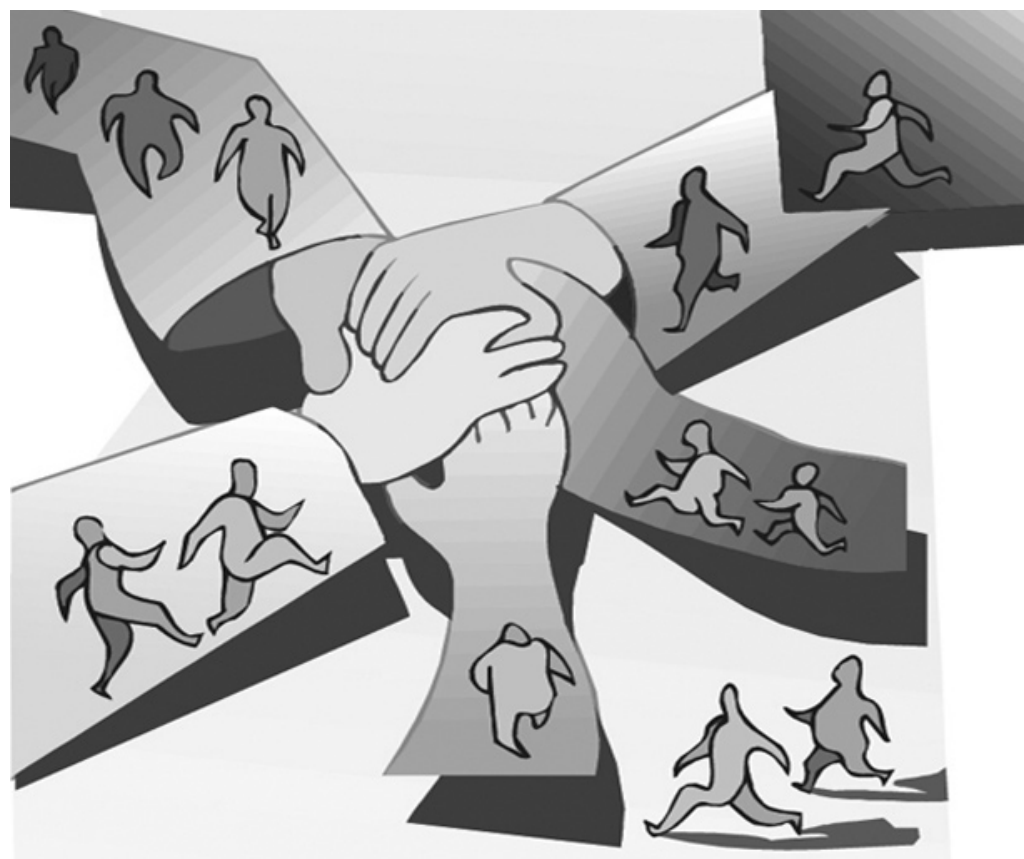


Resumo: Este trabalho analisa a correlação entre o que adolescentes pensam sobre si mesmos e as projeções idealizadas de futuro, tendo como hipótese a manifestação da solidariedade relacionada à construção de um projeto ético de vida: se o despertar para a justiça ocorrer, a participação social solidária tornar-se-á central na formação da personalidade; do contrário, a solidariedade terá valor periférico. O corpo teórico se insere na Psicologia moral e do desenvolvimento. $\mathrm{O}$ método consistiu em depoimento escrito com 396 sujeitos, escolarizados, ambos os sexos, entre 16 e 18 anos. Foram utilizadas três histórias do PROM - Prosocial, Reasoning Objective Measure - e uma dissertação livre sobre como desejariam que suas vidas estivessem daqui a 10 anos. Os resultados apontaram imaturidade pró-social. Há a inclusão do outro nos planos de vida, mas de forma intersubjetiva. Somente uma pequena parcela demonstrou manifestações solidárias. Concluiu-se que condutas pró-sociais dependem da construção moral na infância e na adolescência para as personalidades assumirem perspectivas éticas.

Palavres-chave: Personalidade. Solidariedade. Adolescência. Moral.

\begin{abstract}
This work analyzes the consistence between what young people think about themselves and about their projections into the future. The hypothesis is that solidarity can be a cause to construct an ethical project of life: if justice becomes real in young people's lives, the sympathetic social participation can be central in their personality formation; if not, it would be in a peripherical position. The theorical base is inserted in Moral and Development Psychology. The method consisted on written interviews with 396 individuals of both sexes, between 16 and 18 years old. Three stories of PROM - Prosocial Reasoning Objective Measure - were used and the youngsters were asked to write a text about what kind of life they would like to have ten years from now. The results pointed out to immature individuals in current prosociality. They included other people in their plans, but in an intersubjective way. Just a small parcel of them demonstrated solidarity. The prosociality depends on a consistent moral formation that depends on the moral construction in childhood and adolescence, so that personalities can assume an ethical perspective.
\end{abstract}

Keywords: Personality. Solidarity. Adolescence. Moral.

1 Pesquisa apresentada no Instituto de Psicologia da USP - Departamento de Psicologia Escolar e do Desenvolvimento Humano - para obtenção de título de Doutor, sob a orientação do prof. Dr. Yves de La Taille.
A preocupação com o outro é, antes de tudo, a experiência de uma sensação, de um "estado de espírito", no qual se respeita esse outro como se ele fosse nós mesmos. A preocupação com o outro é somente uma dentre a grande variedade de tendências humanas, e, neste trabalho, se relaciona à temática da formação da personalidade "moral", portanto, no campo da Psicologia do desenvolvimento humano e da Psicologia moral. Fazemos a seguir algumas considerações: a ética seria a reflexão sobre a moral, tal como os povos a desenvolvem. A ética corresponde ao conjunto de ideais que estão associados à busca de uma vida bem sucedida, à realização de projetos, valores que orientam a busca da felicidade, e expressa a "arte de viver", sendo a pergunta que a orienta "como viver?", ou seja, um plano ético é aquele que busca o que traz sentido à vida. Neste estudo, trataremos a ética e a moral dentro de uma opção psicológica, ou seja, como uma se relaciona à outra. Por sujeito moral, entendemos aquele que, por meio da razão, conhece os fins morais, a conseqüência de seus atos e como estes afetam as outras pessoas, além da diferença entre Bem e Mal. 
A motivação para a ação é sempre afetiva, e a dimensão dessa afetividade é o seu valor.
Para a compreensão psicológica de como alguém legitima - dá valor - a conteúdos morais, é preciso entender a perspectiva ética que essa pessoa adota. Para La Taille (2001), numa leitura psicológica, a ética engloba a moral, e "as respostas à pergunta 'como viver?' dependem daquelas dadas ao 'como devo agir?'" (p. 69). É esse mesmo autor que retoma a definição de Ricoeur de que

a perspectiva ética é a perspectiva de uma vida boa, para e com outrem, em instituições justas. Veja que programa completo: a perspectiva de uma vida boa, em que o outro comparece de duas formas - com o outro - seria a idéia de grupo, da cooperação - mas também para o outro - que é a idéia da benevolência, da generosidade. E essa definição não esquece a dimensão política: em instituições justas. (Cortella \& La Taille, 2005, p. 35)

Assim, valorar é uma experiência fundamentalmente humana, que se encontra no centro da escolha de que tipo de vida queremos ter, e, nesse sentido, ter um plano solidário de vida é dar prioridade a certos valores, ou seja, escolher o que é melhor e evitar o que é prejudicial à sociedade como um todo, na tentativa de atingir uma meta proposta. A motivação para a ação é sempre afetiva, e a dimensão dessa afetividade é o seu valor. Segundo La Taille (2002), é a afetividade que produz o querer, ou, como explica Piaget (1994), a força de vontade: "Tal força é essencial para a moralidade, porque é dela que depende o dever" (La Taille, 2002b, p. 127).

Quando se age de modo livre e espontâneo segundo os costumes e valores da cultura, interiorizados de tal forma que parecem pertencer a nossa própria vontade, temos o dever moral (Tugendhat, 1999), conjunto de valores, normas, fins e leis estabelecidos pela cultura que pressupõem o acordo pleno entre a vontade subjetiva e a objetiva, diante daquilo que é, orientado para aquilo que deve ser.

Nesse processo, este estudo nos força a repensar a democracia e a concebê-la como o resguardo das garantias jurídicas de proteção do cidadão contra as arbitrariedades do poder, estimulando-o a assumir papéis participativos, críticos e solidários. Focaremos as discussões na solidariedade. O conceito de solidariedade é relativo ao conceito de comunidade, e sua utilização variada é o resultado de referências correspondentes a grupos particulares, através dos quais os deveres mútuos são definidos de acordo com as suas especificidades e necessidades. Tomamos emprestada a diferenciação que La Taille (1996, 2002b) faz entre ética e moral para estabelecermos a relação entre solidariedade e moral: a moral é o que, de fato, as pessoas seguem, acreditam e fazem, pois ela é um conjunto de regras cujo objetivo é garantir a sobrevivência da comunidade. Assim, as regras são morais porque conferem deveres a cada membro da comunidade, e esses deveres são derivados dos direitos reconhecidos às pessoas. Se a moral corresponde, de fato, à pergunta "Como devo agir?", a resposta necessariamente se traduz por um plano - o Plano Moral considerado pelo sujeito como obrigatório e convencional (La Taille, 2001).

Em seu sentido mais geral, a solidariedade expressa um elo que envolve todos os seres humanos em uma grande comunidade moral, num sentimento de fraternidade entre todos os membros de uma família ou clã. Se considerarmos a moral "um conjunto de regras restritivas da liberdade individual, de caráter obrigatório, cuja finalidade é garantir a harmonia do convívio social" (La Taille, 2002b, p. 16), o princípio da solidariedade entra para o mundo moral com uma grande função, que aponta cada indivíduo como responsável pelas ações, desejos, lutas e méritos de outros indivíduos. 
toda virtude é, pois, história, como toda humanidade, e ambas, no homem virtuoso, sempre coincidem: a virtude de um homem é o que o faz humano, ou antes, é o poder específico que tem o homem de afirmar sua excelência

própria, isto é, sua humanidade. (p. 8)
A solidariedade, neste estudo, será tratada como virtude, sendo que esta se acha relacionada às percepções que fazemos de nós mesmos e que sustentam a idéia de excelência, de uma dimensão que não permite ao sujeito voltar-se para o autointeresse, que fere o juízo de sua dignidade. Assim, a virtude é uma capacidade humana no domínio moral. As virtudes, então, são inerentes ao sentido do humano e relacionam-se às suas ações e atitudes, enfim, aos seus modos de ser.

Segundo Comte-Sponville (1997),

toda virtude é, pois, história, como toda humanidade, e ambas, no homem virtuoso, sempre coincidem: a virtude de um homem é o que o faz humano, ou antes, é o poder específico que tem o homem de afirmar sua excelência própria, isto é, sua humanidade. (p. 8)

A solidariedade será também tratada aqui como virtude pública:

...Se os direitos fundamentais são a igualdade e a liberdade, seja qual for a realização de cada um de ambos os valores, será possível falar de práticas, de atitudes, de disposições coerentes, como a busca da igualdade e da liberdade para todos. A essas disposições é que chamamos de "virtudes públicas. (Camps, 1996, p. 22)

A solidariedade como virtude pública é condição para o exercício da justiça e uma compensação para suas insuficiências, ou seja, a justiça não atende todos, pois é fundamentada na lei e na punição. A solidariedade como virtude política pode permitir a integração de todos, em vista da sobrevivência, dos recursos limitados do Planeta, assim como a realização plena dos ideais democráticos que incluem a cidadania e a busca da justiça.
E para discutir solidariedade num contexto psicológico?

Autores como Comte-Sponville (1997) e Tugendhat (1999) relacionam as virtudes com as disposições do coração ou do caráter. O caráter - ou modo de ser -, as ações e as atitudes estão relacionados à virtude, e esta, por sua vez, é inerente ao sentido do humano:

...Toda virtude é, pois, histórica, como toda a humanidade, e ambas, no homem virtuoso, sempre coincidem: a virtude de um homem é o que o faz humano, ou antes, é o poder específico que tem o homem de afirmar sua excelência própria, isto é, sua humanidade... (Comte-Sponville, 1997, p. 8)

Há várias manifestações da solidariedade que estão associadas às atitudes, comportamentos e caráter humanos. Essas manifestações da identidade pessoal atendem as eternas questões morais: que tipo de pessoa sou e que tipo de pessoa quero ser?

\section{Personalidade e concepções de si}

A formação da esfera moral da personalidade tem constituído historicamente um dos objetivos fundamentais da chamada educação de valores. Se pensarmos no desenvolvimento como o resultado de um processo de interação entre as estruturas, o organismo e o ambiente, pensaremos que a formação moral se integra por influência social e cultural à estrutura da personalidade dos indivíduos, regulando seus comportamentos. Nesse sentido, a análise da personalidade individual não estaria completamente focada na realidade se não fossem levadas em consideração as raízes sociais e as inserções e interações (Puig, 1998). 
O caráter, num sentido moral, é o valor atribuído a um determinado sujeito, ou seja, a leitura ética da sua personalidade (La Taille, 2001).
Essa relação entre moral e personalidade apareceu em estudos no campo da Psicologia e no campo da moralidade desde meados de 1960, e muitos dos desafios à idéia da personalidade eram precisamente aqueles que, segundo Kitwood (1996), poderiam se nivelar à idéia do caráter. Sobre caráter, interessam-nos particularmente as explicações de Kant (Civita, 1999), que tentam conciliar a causalidade natural e a causalidade livre. Para ele, existe um caráter moral, que é o sinal do homem como ser racional, provido de liberdade e que diz o que o homem é capaz de fazer de si mesmo, diferentemente do caráter físico que expressa a condição do humano, do homem como ser natural. A interpretação dessas posições na atualidade gerou controvérsias: distinguir o caráter como uma formação natural e inevitável que o homem traz ao nascer ou considerar o caráter como uma formação derivada das escolhas e, portanto, livre e modificável. Para este estudo, interessa-nos a segunda interpretação. Fugindo desse dualismo, no entanto, Adler (citado por Abbagnano, 1999) considera o caráter como a manifestação objetiva, verificável por meio da experiência social, ou seja, ele só existe se houver a conexão do homem com seu meio. As disposições que constituem o caráter são adquiridas, e só se manifestam socialmente.

O caráter deve ser observado não como parte do que um indivíduo é realmente, mas como um padrão uniforme da apresentação do self. O caráter, num sentido moral, é o valor atribuído a um determinado sujeito, ou seja, a leitura ética da sua personalidade (La Taille, 2001).

Diante disso, adotaremos aqui a seguinte explicação: o caráter é uma manifestação da personalidade, é um elemento que se modifica em função das opções feitas pelo sujeito e que delineiam um projeto de vida. Por personalidade - ou self - entendemos o conjunto de representações de si. Essas representações são sempre valores, imagens que cada um tem de si, e, num sentido psicológico, são entendidas como um investimento de afetividade (La Taille, 2001a, 2002a).

O self é um construtor complexo, de difícil operacionalização, mas que quase todos os teóricos reconhecem como sendo importante, representando aquilo que sentimos como o cerne da personalidade humana e que pode ser chamado tanto de self como de eu, ou de ego... (Biaggio, 1996, p. 77)

Assim, as concepções teóricas de Piaget (1994) e as de Kohlberg (1992) sobre o desenvolvimento moral, as de Turiel (1983) sobre os domínios da moralidade, as de Eisenberg (1982) sobre o desenvolvimento pró-social, os estudos de Hoffman (1984, 1987/1992, 2002) sobre empatia e autoconceito, a teoria de Erikson (1987) sobre adolescência e as de Gilligan (1982) sobre as diferenças de gênero no desenvolvimento moral pretendem explicar que todo processo de construção do sujeito pode ser a expressão da apropriação da experiência histórico-cultural do meio, considerado o desenvolvimento moral como a manifestação da formação moral de uma determinada cultura, inscrita no processo de construção de uma determinada personalidade.

A idéia básica é que as funções e os objetivos dos sistemas sociais na interação não são de um único tipo, de maneira que o objetivo da investigação deve ser a identificação dos sistemas conceituais que coexistem no pensamento social da criança e do adolescente. O que é necessário explicar em qualquer teoria do desenvolvimento 
O problema desencadeador é, portanto, este: acreditando que repousam sobre as novas gerações as noções de justiça social e de um mundo melhor, por que alguns jovens escolarizados se manifestam solidários e outros não? moral é de que maneira um sujeito chega a interiorizar uma série de normas que lhe permitem organizar sua conduta no âmbito social e moral.

\section{Aspectos Metodológicos}

O objetivo principal desta pesquisa é verificar se as virtudes na formação das personalidades jovens representam uma tentativa de superação do abandono da crença na solidariedade. Como um segundo objetivo, temos a compreensão do perfil do jovem brasileiro escolarizado, pretendendo analisar como incidem as variáveis pessoais na consciência entre o que eles pensam que se deve fazer e as projeções idealizadas de vida, no âmbito específico da solidariedade. Entre as variáveis pessoais, pareceu-nos especialmente interessante relacionar à manifestação da solidariedade o sentimento de empatia, o juízo moral, o autoconceito (concepções de si mesmo) e o projeto de vida.

O problema desencadeador é, portanto, este: acreditando que repousam sobre as novas gerações as noções de justiça social e de um mundo melhor, por que alguns jovens escolarizados se manifestam solidários e outros não?

Como hipótese, pensamos que, se os adolescentes têm suas identidades ainda por construir, a manifestação dessa virtude poderá relacionar-se à construção de um projeto ético de vida - que também chamaremos de Plano de Vida (PV) - inserido no desenvolvimento da personalidade moral. Melhor explicando: se o despertar do senso moral para a justiça e a generosidade ocorrerem, a participação solidária do adolescente na sociedade tornarse-á central na formação de sua personalidade e poderá ser um valor essencial em sua vida, ou seja, aqueles que apresentam, em seu projeto de vida, tendências mais humanistas, estariam mais próximos de ações solidárias e, em conseqüência, nas representações que fazem de si mesmos, o outro estaria sempre presente. A personalidade constituída nesses parâmetros seria mais complexa e altruísta, porque seria capaz de entender a alteridade, isto é, seria "capaz de olhar o outro como outro, e não como estranho" (Cortella \& La Taille, 2005, p. 31).

Já os adolescentes que apresentam tendências mais voltadas para os bens de consumo, para a glória pessoal e para o individualismo poderiam estar mais distantes de um plano ético de vida, no qual a solidariedade, como valor moral, ficaria numa posição periférica no seu desenvolvimento. A personalidade assim constituída seria mais egocêntrica, e seus interesses seriam de âmbito exclusivamente privado, incluindo o outro apenas para favorecimento pessoal.

\section{Instrumento de medida:}

A conduta solidária dos adolescentes foi avaliada por meio de um "kit" individual, por escrito, que continha duas partes na seguinte seqüência:

a) PROM - Prosocial Reasoning Objective Measure:

É uma medida objetiva destinada a avaliar o nível de raciocínio moral pró-social, baseada na teoria de Kohlberg, criada por Eisenberg, Carlo e Knight, em 1992. A medida contém sete histórias, cuja essência é um dilema que propõe um conflito de ordem moral ao confrontar as necessidades e desejos do protagonista e dos demais personagens. Após cada história, o sujeito elege um dos três tipos de conduta indicada que aponta o que o protagonista deveria fazer. A situação é passada no tempo presente e possibilita 
ao sujeito colocar-se no lugar do outro e procurar compreender seu ponto de vista. Esse instrumento nos permite discriminar os sujeitos que justificam a situação em função de seus próprios interesses, os sujeitos que se sentem pressionados pela aprovação externa, os que se orientam pelos estereótipos de bem ou mal e, ainda, os sujeitos que têm por meta os critérios de igualdade e a possibilidade de assumirem responsabilidades e anteciparem conseqüências, sejam elas afetivas positivas ou negativas.

Assim, as categorias da pró-socialidade são apresentadas numa escala de maturidadeimaturidade, iniciando com a internalizada (I) como tendência mais amadurecida, seguida da tendência orientada à necessidade $(\mathrm{ON})$, da estereotipada (E), da orientada à aprovação (AO) e, por fim, da hedonista $(H)$, a pró-socialidade mais imatura.

Neste estudo, utilizamos somente três das sete histórias do teste, cujas descrições demandam algum tipo de conduta solidária relativamente comum ao contexto dos adolescentes.

b) Depoimento escrito:

Essa forma de dissertação livre é favorável à apuração das disposições de suas condutas individuais que podem levá-los a ações solidárias ou não. O depoimento é um espaço aberto para que os jovens se expressem sobre sua visão de mundo e quais valores morais acreditam ser imprescindíveis para o bem comum, qual sua concepção de realização pessoal, de participação e transformação social. Diferentemente da primeira parte, esse depoimento tem um caráter de futuro, ou seja, o sujeito faz uma prospecção de seus planos de vida em termos do que deseja, em que ele é o protagonista. A possibilidade de $\mathrm{o}$ adolescente projetar-se num futuro próximo permite um exercício bastante saudável de organização e planejamento de suas ações, nos quais a idealização de um projeto de vida se apresenta como uma situação-problema hipotética, em que o sujeito deverá refletir e escrever um depoimento considerando o seguinte: pense na pessoa que você é hoje. Imagine você mesmo daqui a 10 anos. Descreva como você desejaria que estivesse sua vida.

\section{Sujeitos:}

Para a Psicologia do desenvolvimento, a adolescência marca o início de um período de vida no qual aparece maior número de preocupações interpessoais e maior consistência entre o juízo moral e a ação. A faixa etária dos sujeitos selecionados é de 16 a 18 anos, todos escolarizados, cursando o $3^{\circ}$ ano do ensino médio, fase na qual se preparam para suas escolhas profissionais e inserção no mercado de trabalho. Os sujeitos são de duas escolas particulares de grande porte do Estado de São Paulo, de classe média e média-alta, que valorizam o estudo como forma de inserção do indivíduo na sociedade. A aspiração maior dessa clientela é o ingresso nas universidades de maior concorrência, sejam públicas, sejam particulares.

A amostra tem 174 jovens do sexo masculino e 222 do sexo feminino. Total geral: 396 sujeitos. Todos assinaram o Termo de Consentimento Livre e Esclarecido.

\section{Procedimentos:}

O roteiro de investigação apresentou dois pontos relevantes para a discussão que servem como questões norteadoras:

- Como incidem as condutas solidárias dos adolescentes nos ditos Planos de Vida e ainda 
explorar quais são as principais variáveis que explicam a solidariedade.

- A relação entre a cognição - juízo moral, autoconceito - e os sentimentos morais empatia e altruísmo.

Dessa forma, o "kit" possibilitou três segmentos de estudo:

Estudo 1 - verificação das tendências prósociais nas personalidades dos jovens.

Em primeiro lugar, a conduta solidária que o jovem pode ter no momento presente de sua vida foi avaliada por meio do PROM. A variável empatia que aparece nessa medida permitiu comparar sua importância nas concepções presentes com o juízo moral, por meio da identificação do sujeito com a situação proposta. Com os resultados dessa primeira parte, pudemos estabelecer categorias de grupos de adolescentes de acordo com as classificações do instrumento, o que nos permitiu construir um prérequisito para a análise do depoimento escrito, partindo do pressuposto de que um adolescente classificado como hedonista pelo PROM não deveria construir um plano solidário de vida, mas o adolescente com valores internalizados, sim.

Estudo 2 - verificação das projeções futuras.

O autoconceito e o Plano Solidário de Vida dos adolescentes foram avaliados através do depoimento livre que, resumidamente, apresentou a visão que cada um dos entrevistados tinha de si mesmo, das qualidades que possuía e o que almejava alcançar no futuro. Como a proposta sugeria uma perspectiva de futuro, pudemos compreender o lugar que o outro ocupava em seus planos de vida, aquilo que o motivava para a realização dos ideais, podendo, assim, traçar um roteiro de como desejaria percorrer sua vida.

Estudo 3 - verificação da correlação presentefuturo.

a) Foi constatado o índice percentual de correlação entre os resultados do PROM e os Planos de Vida dos jovens, inicialmente, entre as categorias do teste e os sujeitos com projetos de vida conectados ao outro; em seguida, foram verificados os projetos de vida, que foram agrupados, nos resultados gerais, por segmento, gênero e idade.

b) Em separado, verificou-se a correlação entre PVS e PNS com categorias de prósociabilidade do PROM, respectivamente, para resultados gerais, por gênero e por idade.

c) Também a correlação de cada história do teste - categorias pró-sociais - com os sujeitos com Planos de Vida Conectados e Planos de Vida Desconectados e com os PVS e PNS.

Resultados

Apresentamos a seguir os resultados por segmento:

a) Estudo 1 - Verificação das tendências pró-sociais nas personalidades dos jovens por meio do PROM - Quem sou eu?

Obtivemos, como resultado geral, 47,81\% de jovens inquiridos na categoria internalizada, $25,63 \%$ na categoria orientada à necessidade, $10,48 \%$ na categoria hedonista, $14,69 \%$ na categoria estereotipada, e 1,39\% na categoria orientada à aprovação. Na comparação entre os resultados dos meninos e das meninas, notamos uma tendência superior nas meninas - 51,88\% para a categoria internalizada em relação a 42,63\% nos meninos para a mesma categoria - ainda que essa diferença não seja muito significativa. 
As formas em que o outro é apresentado vão desde relacionamentos afetivos, de âmbito particular - família, pais, companheiro(a), amigos, filhos - até relacionamentos sociais mais comunitários, de âmbito coletivo - ajudar pessoas, participar de projetos sociais ou contribuir com a sociedade.
O índice superior para a categoria internalizada é positivo, e evidencia que esses sujeitos demonstraram uma tendência a ações pró-sociais que podem ser explicadas por uma aflição empática, de caráter moral, portanto, caracterizando-se pela ajuda a alguém inquieto, que esteja sofrendo ou que apresente mal-estar por algum motivo. Tomamos o conceito de empatia, segundo a perspectiva adotada por Hoffman (2002), como uma reação afetiva para com o outro, como sentimentos que são congruentes com a situação de outra pessoa. Empatia é atribuir, portanto, valor aos sentimentos alheios, e a pró-socialidade internalizada aponta pessoas que se guiam mais por princípios pessoais, por critérios de igualdade, por assumirem a responsabilidade e por anteciparem as conseqüências, sendo elas positivas ou negativas para o sujeito.

Porém, os índices percentuais não são absolutos. Há categorias híbridas, ou seja, somadas à pró-socialidade internalizada, aparecem outras categorias, mostrando que os aspectos relacionados a valores internalizados, simpatia, reciprocidade generalizada, afetos positivo e negativo e tomada de perspectiva não são manifestações consistentes, já que se misturam a patamares menos amadurecidos. Dos 47,81\% apontados anteriormente, destacamos somente 39,39\% na pró-socialidade internalizada.

A segunda categoria mais evidente nos resultados é a pró-socialidade orientada à necessidade, tanto para os meninos como para as meninas. A manifestação dessa tendência significa uma inclinação para as necessidades físicas e psicológicas, o que é relativamente comum nos resultados desse teste, como ocorreu em estudos já realizados (Carlo, Eisenberg, \& Knight, 1992; Carlo, Eisenberg, Koller, Silva \& Frohlich, 1996), o que revela uma característica própria do amadurecimento da adolescência. b) Estudo 2 - verificação das projeções futuras - Quem eu quero ser?

Os jovens demonstraram os valores que acreditavam essenciais para suas construções de vida, confirmando a idéia de que, no processo civilizatório, o reconhecimento do outro é fundamental, e aparece relacionado às necessidades afetivas, ao reconhecimento dos direitos humanos e ao sistema social como um todo. Assim, 82,32\% incluem o outro de alguma forma em seus planos futuros - Plano de Vida Conectado confirmando a idéia da importância em fazer representações de si e projetar uma vida na qual o outro esteja sempre presente. As formas em que o outro é apresentado vão desde relacionamentos afetivos, de âmbito particular, até relacionamentos sociais mais comunitários.

Os depoimentos que não mencionam o outro em seus Planos de Vida constituem $17,68 \%$ da amostra, e apresentam motivações de caráter material e valorização somente profissional, como a realização financeira, o curtir a vida e ser bem sucedido, o que expressa a obtenção de glória pessoal. Na verificação das projeções futuras para Planos de Vida Conectados ou não, percebeu-se que, na separação por gênero, os meninos são mais desconectados do que as meninas. Do total de meninos, 29,89\% apresentam PV Desconectado em relação a $8,11 \%$ do total das meninas.

Foram as nuances na manifestação da inclusão do outro que permitiram diferenciar os elementos valorados pelos jovens. As formas em que o outro é apresentado vão desde relacionamentos afetivos, de âmbito particular - família, pais, companheiro(a), amigos, filhosaté relacionamentos sociais mais comunitários, de âmbito coletivo - ajudar pessoas, participar de projetos sociais ou contribuir com a sociedade. O reconhecimento do outro 
aparece em relacionamentos baseados na cognição, em que a valorização dos direitos é estendida a todos, como membros de uma comunidade, com base na afetividade, como a concretização de necessidades e contribuição com a vida comunitária.

Definimos algumas categorias, de acordo com as respostas:

a) Manter contato com sua família no futuro $-9,87 \%$;

b) Constituir família feliz, casando e tendo filhos - 30,03\%;

c) Ter um companheiro(a), mantendo relacionamento afetivo como casal $15,25 \%$;

d) Manter os mesmos amigos - 11,47\%;

e) Independência - o outro aparece mencionado pela negação - 9,20\%;

f) Plano de Vida Solidário - desejo de um projeto de vida com participação social e envolvimento solidário - 23,29\%.

Esses percentuais indicam que, se os altos índices para a conexão com o outro foram relevantes, essa inclusão demonstrou não ser suficiente para a projeção de projetos éticos no futuro. A soma das categorias que apontam a família - atual ou construída amigos e companheiro(a) é $67,52 \%$, o que demonstra que os jovens valorizam aspectos intrapessoais que apontam interesses comuns e corporativistas. A afetividade e a motivação são direcionadas a pessoas próximas e conhecidas.

Para a categoria Plano de Vida Solidário, estabelecemos ainda subcategorias para as respostas:

a) Ajudar pessoas que precisam ou menos favorecidos - 22,37\%;

b) Retribuir aos pais a dedicação, o conforto e o apoio recebidos $-7,69 \%$;

c) Ser uma pessoa melhor - demonstra a compreensão da necessidade do amadurecimento e a superação no desenvolvimento pessoal, além da necessidade de participação social, já que, para ser considerado melhor, deve haver parâmetros de comparação que só ocorrerão na vida em sociedade, portanto, há um sentido de valor moral - 7,97\%;

d) Buscar a justiça - é a virtude mais valorizada e idealizada nas sociedades; é a condição para possibilitar a convivência e a ação conjunta dos homens - 2,71\%;

e) Contribuir para a melhoria do País - o exercício da cidadania é uma manifestação de valor moral, pois o outro está colocado no plano da responsabilidade - 1,71\%

f) Ser útil à Humanidade - 8,55\%;

g) Realizar atividades voluntárias - virtude da caridade, que demonstra desprendimento de bens materiais e compromisso social 7,69\%;

h) Participar de causas sociais - há o sentido implícito de buscar um mundo melhor, resolvendo as mazelas sociais - 2,14\%;

i) Viver uma vida justa e honesta - sentido político e participativo, mencionando duas virtudes que são fundamentais para a vida em sociedade $-1,28 \%$;

j) Ser feliz - retomada do sentido aristotélico de Felicidade e, portanto, apresenta um valor moral - 37,89\%.

\section{Essa imagem de Felicidade, inocência e paz que construímos como um presépio permanente no meio de nossas casas é a perfeição que nunca alcançamos nem alcançaremos, pois ser insatisfeitos é para nós definitório. (Calligaris, 2000, p. 66)}

Essas subcategorias remetem às explicações de Hoffman (2002) sobre a correlação positiva entre a aflição empática com o comportamento auxiliador do indivíduo manifestação de ajuda. A aflição empática, segundo o autor, é considerada uma ação moral pró-social, pois implica ajudar alguém 
que está em sofrimento, e, à medida que se manifesta a conduta de ajuda, há o alívio da vítima, o que, por sua vez, traz alívio empático para quem ajudou.

Para Hoffman (2002), não basta simplesmente que o observador sinta aflição empática e deseje ajudar, porque, com essa manifestação, também surgem motivos egoístas que competem com a aflição empática e que podem excluir a ajuda, levando o indivíduo a esforçar-se para evitar o sentimento empático. Isso pode ter ocorrido nas projeções dos sujeitos, motivo pelo qual os índices dessas categorias aparecem muito pouco consistentes em relação ao total da amostra. Assim sendo, uma ajuda que se baseia na empatia é sempre pró-social, mas a pró-socialidade é mais imatura.

Não foram detectadas diferenças consideráveis entre os gêneros.

c) Estudo 3 - verificação da correlação presente-futuro - Quem eu sou hoje implica quem serei amanhã?

Pudemos confirmar nossa hipótese numa pequena parcela dos sujeitos: tendências mais humanistas - categoria pró-social internalizada - trazem planos de vida mais éticos, nos quais o outro é um elemento catalisador e sempre presente.

Do total de sujeitos entrevistados, temos $32,83 \%$ que manifestaram pró-sociabilidade internalizada e conexão com o outro em seus Planos de Vida, de forma absoluta. Se tomarmos a somatória dos sujeitos enquadrados nas categorias internalizada absoluta e internalizada híbrida, temos 39,69\% de sujeitos na mesma correlação.

Fazemos ainda a observação de que, apesar de a categoria pró-social orientada à necessidade ser considerada mais imatura, ela ainda sim, é pró-social, e aparece com alto índice percentual no quadro de correlação geral - 20,75\% de sujeitos. Isso nos confere outro cruzamento: somando-se as gradações pró-sociais, ou seja, a correlação dos índices das categorias do PROM e os Planos de Vida Conectados, pode-se confirmar a hipótese. São 74,5\% do total (pró-sociabilidade internalizada, orientada à necessidade, orientada à aprovação, estereotipada correlacionada aos Planos de Vida Conectados). Abstraiu-se dessa somatória a categoria hedonista, considerada a mais imatura na gradação pró-social; com essa somatória, temos uma mudança de cenário: os índices são altos para a correlação.

Justificamos essa possibilidade de análise, a partir da somatória, relembrando que as emoções pró-sociais agrupam sentimentos relacionados com o interesse, a consideração e o sentido de responsabilidade pelo bemestar e pelos direitos dos demais. Esse interesse se manifesta fundamentalmente por meio de emoções como a empatia e o afeto. A empatia nesse estudo é fundamental, pois constitui o ponto de partida das emoções pró-sociais. Podemos dizer que a empatia é a dimensão da personalidade dos jovens pesquisados, que implicou a capacidade para se identificarem, compreenderem e se comoverem frente aos sentimentos e emoções dos demais e para entenderem os pensamentos, motivos e pontos de vista alheios como divergentes dos seus próprios, mas igualmente válidos.

Em termos gerais, a empatia pode estenderse a todas as idades como a capacidade para "tomar o lugar do outro" e entender como o outro se sente ou como pensa. Essa manifestação de empatia constitui um dos eixos de suporte mais importantes do comportamento moral, e, neste estudo, pode 
ser evidenciada nas representações que os adolescentes fazem de si mesmos.

No processo de desenvolvimento da personalidade, a aceitação dos demais é uma das fontes provedoras de auto-estima mais importantes, ou seja, o afeto que provém das pessoas que desempenham papéis significativos na vida do sujeito fazem com que este vá formando a concepção de si com valores dispostos ao vínculo e à conexão com as pessoas de forma central em suas vidas (Puig, 1998). Nesse processo de formação, conforme o sujeito é descrito e tratado, começa a reconhecer-se como indivíduo, a descobrir quem é na sociedade e a reconhecer que importância tem para os outros.

O projeto pessoal de auto-posição exige como condição necessária, ainda que não suficiente, a auto-estima do sujeito, a consciência de que pode ter distintos projetos capazes de idealizar e que conta com certa capacidade para realizá-los. Educação moral significaria, nesse sentido, ajudar a pessoa a que se sinta em forma, desejosa de projetar, envolvida com seus projetos de auto-realização, capaz de levá-los a cabo e consciente que para isso necessita contar com outras pessoas igualmente estimáveis... (Cortina, 1995, p. 7)

\section{Discussão}

As temáticas parecem ser decisivas para suscitar a solidariedade, e, na resposta à pergunta "quem sou eu?", os jovens demonstraram que ainda estão presos às próprias experiências.
A formação da identidade e a busca de sentido para o si-mesmo estão relacionadas à capacidade de estabelecer compromissos. O processo de adaptação às regras do mundo adulto, diretamente associado ao desenvolvimento cognitivo, permite ao jovem conceber projetos de vida cujas metas são a auto-afirmação, a imitação de modelos significativos e a participação em círculos sociais. Para atingir essas metas, o sujeito deverá conhecer razoavelmente o tipo de pessoa que é, quais valores e crenças importam para a sua vida, obter uma visão coerente de suas atitudes, capacidades e de suas formas de reagir aos outros e de ser percebido por eles. Além disso, em sua vida em sociedade, deverá admitir os direitos humanos como o reconhecimento do direito a ser humano: "é um estatuto consciente e voluntário que os homens devem moralmente conceder uns aos outros" (Savater, 2000, p. 301).

Como primeiro item de discussão das tendências de personalidade dos jovens, encontramos manifestações pró-sociais menos amadurecidas, que se misturam às mais amadurecidas. Isso aponta uma variedade de compreensões da solidariedade, que se aplica a diferentes situações, como, por exemplo, nas que apresentam hipoteticamente a aquisição de um bem material, em que a tendência pró-social é imatura, assim como em situações que se referem à obtenção de sucesso e fama. Já em temáticas que envolvem tratamento de injustiça em ambientes escolares, mais próximas da vivência pessoal dos jovens, a tendência pró-social é mais amadurecida e internalizada. Segundo Hoffman (2002), as pessoas deduzem se a vítima merece estar nessa condição e ainda baseiam seus julgamentos na reputação pessoal ou em estereótipos sobre seu grupo étnico, e isso pode afetar a reação empática do observador. As temáticas parecem ser decisivas para suscitar a solidariedade, e, na resposta à pergunta "quem sou eu?", os jovens demonstraram que ainda estão presos às próprias experiências.

Os estudos sobre solidariedade mostram ainda que ela pode se manifestar como um interesse mais subjetivo por parte de quem fez a ação solidária, que espera reconhecimento para si, no qual a participação pessoal, numa situação qualquer, depende do que dela resulta para a pessoa interessada. A decisão de 
participar seria baseada na ação voluntária, mas essas ações seriam reduzidas a "estados" dos sujeitos, nos quais a realidade ficaria atrelada a percepções ou representações do mesmo, à sua subjetividade. Por subjetivo, apresentamos a definição de Abbagnano (1999) que se refere a "uma representação da relação entre as coisas e nós, ou seja, uma relação com quem as pensa" (p. 922).

Nos resultados da pesquisa, observamos que a responsabilidade social fica em segundo plano, e a busca pela eqüidade aparece no interesse de poucos. Houve correspondência entre a produtividade e a recompensa pessoal, ou seja, os depoimentos apontaram que os sujeitos esperam que haja premiação pela produção e desempenho, assim como o esforço para uma formação profissional. $\mathrm{Na}$ resposta à pergunta "quem eu quero ser?", os jovens demonstraram que querem ser reconhecidos por suas ações.

A partir das teorias que explicam a manifestação solidária, observa-se que o contexto subjetivo da solidariedade só se completa com os sentimentos de pertencimento e reconhecimento. A hipótese básica é que o desenvolvimento da identidade está conectado às formas particulares de reconhecimento de outros sujeitos, sendo que esse reconhecimento ao outro só é válido se o sujeito reconhece a si próprio como outra pessoa. O processo de reconhecimento para a formação da personalidade moral vem associado ao reconhecimento concreto das necessidades do sujeito, e isso forma a base da dignidade social, pois não só os direitos individuais são garantidos mas também os direitos políticos da participação. A necessidade de reconhecimento é também a necessidade de inclusão e de autorespeito - esse sentimento aparece nas respostas dos adolescentes da pesquisa que possibilita ao sujeito poder manifestar suas habilidades e particularidades; é por meio do reconhecimento que o sujeito pode compartilhar, de forma intersubjetiva, os valores pessoais que contribuem para a vida em comunidade (Thome, 1999). O relacionamento recíproco de reconhecimento é constitutivo da formação da identidade, e caracteriza-se como um "processo civilizatório" que permite o aumento do nível de individualização (Thome, 1999).

Para Hoffman (1984) e seus colaboradores, o motivo principal latente em toda a ação social é o da manutenção da pessoa, ou seja, ser reconhecido é ser, de alguma forma, diferenciado. Em outras palavras, sugerese que todo indivíduo tem uma grande necessidade de aprovação, de atenção e de afirmação frente aos outros, e descobrirá ou criará algum mecanismo para obtê-las.

O ato solidário poderia ser entendido como uma realização interna ou sentimento de valor, porque está associado ao desejo e ao prazer obtido na satisfação de tal desejo, sugerindo provavelmente, objetivos mais individualistas, e a motivação para a ação seria sempre vinculada a interesses próprios. A solidariedade estaria mais próxima da virtude da generosidade, que é "mais subjetiva, mais singular, mais afetiva" (Comte-Sponville, 1997, p. 97). Nesta última, existe o desejo de ajudar, mas a ação generosa produz o regozijo e eleva a auto-estima, fazendo com que o sujeito se sinta gratificado com sua atitude.

A solidariedade pode também assumir uma característica corporativista, que projeta um "individualismo de grupo", uma forma de se considerar parte de um grupo - etnia, religião ou Estado - e manifestar obrigações para com ele.

$\mathrm{Na}$ pesquisa, foram constatadas manifestações de conexões com o outro, que, contudo, são da ordem do privado e demonstram uma orientação solidária para o corporativismo, visando a interesses comuns, não desvinculados dos seus próprios, com 
Os elementos empáticos e cognitivos se ativam

mutuamente na formação da identidade. Assim, na resposta à pergunta "quem eu quero ser?", os adolescentes mostraram que a tendência humanista é relevante. índices pouco significativos para os Planos Solidários de Vida que apresentaram nas análises manifestações altruístas deficitárias, enfocando a solidariedade num estágio menos evoluído, que inclui somente a ajuda ao outro necessitado, sem envolvimento em grandes causas sociais ou projetos políticos. Esse resultado pode, de certa forma, confirmar as conclusões observadas na pesquisa do Instituto ISME (2005), que apontam uma tendência do adolescente voltada para o espaço privado, porque talvez "o espaço público lhe apareça como ameaçador, pois nele enxerga mais adversários do que amigos e mais agressividade do que diálogo" (La Taille \& Hartok-de-la-Taille, 2005, p. 45).

No âmbito interno de uma comunidade, pode haver uma tradição de pensamento, de costumes e de lealdade que permite construir algum princípio válido para todos os seus membros. Esses princípios construídos não têm um valor em si, mas somente adquirem força e significado no interior da comunidade, e, nesse sentido, podemos pensar em solidariedade somente com e para os membros do grupo, que é identificado naquilo que é socialmente aceito (Hobsbawn, 1999).

Essa também é uma manifestação de solidariedade, mas que pode antever conseqüências graves no plano político e democrático, como o fechamento do grupo em si mesmo, a tal ponto que qualquer outro grupo poderia ser considerado falso em seus princípios, ou ainda, um "inimigo" em potencial, ao qual, eventualmente, dever-se-ia combater. Muitos conflitos históricos tiveram, de certa forma, caráter corporativista, pois a luta pelo poder pertence a quem tiver "força" suficiente para se sobressair aos outros, seja ele e o poder econômico, cultural, militar e até mesmo o da mídia. É claro que, visto no geral, essa idéia não é compatível com os ideais éticos de reciprocidade, humanismo e democracia, e talvez seja por isso que ComteSponville (1997) afirme que a solidariedade "é demasiado interessada ou demasiado ilusória para ser uma virtude" (p. 99). No caso de adolescentes, essa seria uma manifestação forte, pois é muitas vezes pelo grupo que o jovem constrói sua identidade e é pelo grupo que sustenta suas necessidades de convívio social e aproximação sexual.

Foi verificado também que os Planos de Vida dos entrevistados apresentaram resultados consistentes de inclusão do outro, para ambos os gêneros. Foi significativa a presença da conexão com outras pessoas nos projetos de vida dos jovens na apuração geral, o que destaca uma ligação com a vida em sociedade e um senso de realidade que pode mobilizá-los para a descentralização e para a entrada no mundo da produção social. A tendência humanista fica constatada, e supera a tendência materialista. Podemos dizer que o afeto empático está associado a um princípio moral em que a contribuição da empatia para esses princípios é o que converte a prósociabilidade em representações cognitivas e o que lhe dá força. Os elementos empáticos e cognitivos se ativam mutuamente na formação da identidade. Assim, na resposta à pergunta "quem eu quero ser?", os adolescentes mostraram que a tendência humanista é relevante.

Tomamos as explicações de Bariaud (1997) sobre as concepções de "si" que se constroem principalmente sobre a base de informações retiradas a partir das experiências das interações sociais e individuais, percebidas em si mesmas e percebidas também nas atitudes e opiniões dos outros a seu respeito. Essas concepções vão se transformando ao longo da infância e da adolescência, no desenvolvimento das capacidades cognitivas, da multiplicação e diversificação das experiências e da cognição das categorias conceituais provenientes da cultura, que 
Ihes dá sentido, por isso, a conexão com o outro é fundamental, pois, na construção de sua personalidade, o sujeito é um ser humano concreto que opera em um contexto sociocultural específico de normas e valores, de sistemas institucionais e de atividades sociais, nas quais assume responsabilidades e compromissos e representa determinados papéis.

\section{Conclusões}

A lógica pró-social é orientada para o outro em função de suas necessidades ou baseada na adoção de uma perspectiva alheia que se traduz por uma aproximação ou antecipação dos princípios de solidariedade. Os adolescentes pesquisados puderam demonstrar, por meio dos questionamentos, uma continuidade em seu modo de pensar, passando do presente ao futuro e estabelecendo relações entre suas identidades, decisões e compromissos sociais e pessoais. Os seus Planos de Vida apresentaram objetivos educativos, pessoais e/ou profissionais e um conjunto de valores e crenças que direcionaram esforços para a possibilidade da inserção na vida em sociedade, vida essa que deverá ser transversalizada pela ética como um querer ser, como uma tomada de posição voluntária.

Nos resultados gerais, a hipótese da pesquisa não se confirma, pois há forte demonstração de inclusão do outro, mas que não sustenta a construção de projetos de vida permeados pela virtude da solidariedade. Verifica-se que a simples menção da inclusão do outro não é garantia para a formação da personalidade moral com perspectivas de um Plano Solidário de Vida. A hipótese é porque a forma como o outro comparece nas representações dos sujeitos é sempre de caráter mais subjetivo - pessoas conhecidas e as projeções futuras que também seguem essa tendência, não se ampliam para a sociedade como um todo, mas limitam-se a círculos familiares e de amizade.

Por fim, podemos afirmar que, ainda que na sociedade atual haja uma tendência ao individualismo, isso não pode distanciar os indivíduos de uma posição voltada para o "público", como reclusão na privacidade. Segundo Savater (2000),

O coletivismo não se caracteriza por ser uma forma de produção de bens nem de distribuição ou propriedade dos mesmos, mas pela imolação instrumental da autonomia individual aos fins da entidade coletiva, vista como algo mais significativo e meritório do que o conjunto de seus membros. (p. 299)

No campo da ética, o individualismo deverá apresentar a internalização moral da autonomia e da responsabilidade do sujeito para além de sua pertinência a um determinado grupo. Segundo Savater (2000), só se pode ser virtuoso individualmente, ou seja, a excelência da virtude, o que constitui sua dignidade, é o fato de que ninguém pode ser virtuoso pelo outro e nem ser virtuoso como o outro. Nesse sentido, o resgate da figura do herói explica o que concebemos pela formação moral.

\footnotetext{
O herói é o indivíduo autônomo que, em cumprimento ou invenção da mais alta moralidade, decide viver sua peripécia pessoal e social como uma aventura irrepetível. Não procura a originalidade a qualquer preço, nem a divergência ou a coincidência com a mesma, mas o estabelecimento da sua história como própria, como fruto do amor individualizante. (Savater, 2000, p. 297)
}

Para a moral, o sentido coletivista, a garantia dos direitos humanos e o "fazer política" equivalem a alcançar uma sociedade melhor como unidade de destino comum. 


\section{Denise D'Aurea-Tardeli}

Doutora em Psicologia Escolar e Desenvolvimento Humano, prof. da UMESP Endereço para correspondência:

R. República do Equador, 12 - ap. 21 - Ponta da Praia - Santos - SP - CEP: 11030-150

E-mail: denise.tardeli@metodista.br

Recebido 11/07/2007 Reformulado 26/12/2007 Aprovado 16/01/2008

Referências
Abbagnano, N. (1999). Dicionário de filosofia. São Paulo: Martins Fontes.

Bariaud, F. (1996). Le développement des conceptions de soi. In H. Rodriguez-Tomé \& A. M. B. Biaggio, Self e moralidade. In Z. Trindade \& C. Camino (Orgs.). Cognição social e juízo moral (Coletânea da ANPEPP, pp. 77-91). Rio de Janeiro: ANPEPP.

Biaggio, A. M. B. (1996). Self e moralidade. In Z. Trindade \& C. Camino (Eds), Cognição social e juízo moral (Coletânea da ANPEPP, pp. 77-91). Rio de Janeiro: ANPEPP.

Calligaris, C. (2000). A adolescência. São Paulo: PubliFolha.

Camps, V. (1996). Virtudes públicas. Madrid: Espasa Calpe AS.

Carlo, G., Eisenberg, N., \& Knight, G. P. (1992). An objective measure of adolescent's prosocial moral reasoning. Journal of Research on Adolescence, (2), 331-249.

Carlo, G., Eisenberg, N., Koller, S. H., Silva, M. S., \& Frohlich, C. B. (1996). A cross-national study on the relations among prosocial moral reasoning, gender role orientation and prosocial behaviors. Developmental Psychology, (32), 231240.

Civita, V. (1999). Emanuel Kant (Os Pensadores). São Paulo: Nova Cultural.

Cortella, M. S., \& La Taille, Y. (2005). Os labirintos da moral. São Paulo: Papirus.

Cortina, A. La educación del hombre y el cuidado. Revista Iberoamericana de Educación - Democracia y Educación 1. Disponível: www.oei.org

Comte-Sponville, A. (1997). Pequeno tratado das grandes virtudes. São Paulo: Martins Fontes.

Erikson, E. (1987). Identidade: juventude e crise. Rio de Janeiro: Guanabara.

Eisenberg, N. (1982). (Ed.). The development of prosocial behavior. New York: Academic Press.

Gilligan, C. (1982). In a different voice: Psychological theory and women's development. Cambridge, MA: Harvard University Press.

Hobsbawn, E. (1999). A era dos extremos - o breve século XX - 1914-1991 (pp. 314-390). São Paulo: Companhia das Letras.

Hoffman, M. L. (1982). Development of prosocial motivation: Emphaty and Guilt. In: N. Eisenberg, The development of prosocial behavior (pp. 281-313). New York, Academic Press.

Hoffman, M. L. (1984). Interaction of affect an cognition in empathy. In C. E. Izard, J. Kagan, \& R. B. Zajonc (Eds), Emotions, cognitions and behavior (pp. 103-131). Cambridge: Cambridge University Press.
Hoffman, M. L. (1992). La aportación de la empatía a la justicia y al juicio moral. In N. Eisenberg \& J. Strayer (Orgs), La empatía y su desarrollo. Bilbao, Spain: Desclée de Brower.

Hoffman, M. L. (2002). Desarollo moral y empatía - implicaciones para la atención y la justicia. Barcelona: Idea Books.

Kitwood, T. (1996). La preocupación por los demás - Una nueva Psicología de la conciencia y la moralidad (Cap. 1 e 4). Bilbao, Spain: Biblioteca de Psicologia; Desclée de Brower.

Kohlberg, L. (1992). Psicologia del desarrollo moral. Bilbao, Spain: Desclée de Brower.

La Taille, Y. (2001). A questão da indisciplina: ética, virtudes e educação. In P. Demo, La Taille, Y., \& J. Hoffman, Grandes pensadores em educação - o desafio da aprendizagem, da formação moral e da avaliação (pp. 67-98). Porto Alegre: Mediação.

La Taille,Y. (2002a). Cognição, afeto e moralidade. In M. K. Oliveira, D. T. R. Souza, \& T. C. Rego (Orgs.), Psicologia, educação e as temáticas da vida contemporânea (pp. 135-158). São Paulo: Moderna.

La Taille, Y. (2002b). Vergonha - a ferida moral. Petrópolis, RJ: Vozes.

La Taille, Y., \& Hartok-de-la-Taille, E. (2005). Valores dos jovens de São Paulo (Relatório de Pesquisa). São Paulo: Instituto ISME.

Piaget, J. (1994). O juízo moral na criança. São Paulo: Summus.

Puig, J. M. (1998). A construção da personalidade moral. São Paulo: Ática.

Savater, F. (2000). Ética como amor-próprio. São Paulo: Martins Fontes.

Thome, H. (1999). Solidarity: Theorical perspectives for empirical research. In K. Bayertz, Solidarity (pp. 101-132). Dordrecht: Kluwer Academic Publishers.

Tugenhat, E. (1999). Lições sobre ética (3a ed.). Petrópolis, RJ: Vozes.

Turiel, E. (1983). The development of social knowledge - Morality and convention (Chap. 4, 7 e 9). Cambridge: Cambridge University Press.

Zajonc, R. B. (1982). Development of prosocial motivation: Empathy and guilt. In N. Eisenberg, The development of prosocial behavior (pp. 281-313). New York: Academic Press.

Zajonc, R. B. (1992). La aportación de la empatía a la justicia y al juicio moral. In Eisenberg, N. \& Strayer, J. (Eds), La empatía y su desarrollo. Bilbao: Desclée de Brower.

Zajonc, R. B. (2002). Desarollo moral y empatía - implicaciones para la atención y la justicia. Barcelona: Idea Books. 